\title{
BMJ Open Seroprevalence of SARS-CoV-2 antibodies in children of United Kingdom healthcare workers: a prospective multicentre cohort study protocol
}

\author{
Michael Corr (D) , ${ }^{1}$ Sharon Christie, ${ }^{2}$ Chris Watson, ${ }^{3}$ Julieann Maney, ${ }^{4}$ \\ Derek Fairley, ${ }^{5}$ Shamez N Ladhani, ${ }^{6}$ Mark David Lyttle (1),${ }^{7,8}$ Lisa McFetridge, ${ }^{9}$ \\ Hannah Mitchell, ${ }^{9}$ Michael David Shields, ${ }^{3}$ Claire McGinn, ${ }^{10}$ James McKenna, ${ }^{5}$ \\ Peter Mallett, ${ }^{10}$ Kathryn Ferris, ${ }^{10}$ Gala Rowe-Setz, ${ }^{10}$ Rebecca Moore, ${ }^{10}$ \\ Steven Foster, ${ }^{11}$ Jennifer Evans, ${ }^{12}$ Tom Waterfield ${ }^{3,13}$
}

To cite: Corr M, Christie S, Watson C, et al. Seroprevalence of SARS-CoV-2 antibodies in children of United Kingdom healthcare workers: a prospective multicentre cohort study protocol. BMJ Open 2020;10:e041661. doi:10.1136/ bmjopen-2020-041661

- Prepublication history and additional material for this paper are available online. To view these files, please visit the journal online (http://dx.doi. org/10.1136/bmjopen-2020041661).

Received 16 June 2020 Revised 18 August 2020 Accepted 30 October 2020

Check for updates

(c) Author(s) (or their employer(s)) 2020. Re-use permitted under CC BY-NC. No commercial re-use. See rights and permissions. Published by BMJ.

For numbered affiliations see end of article.

Correspondence to

Dr Tom Waterfield;

t.waterfield@qub.ac.uk

\section{ABSTRACT}

Background A novel coronavirus SARS-CoV-2 has been responsible for a worldwide pandemic. Children typically have very mild, or no, symptoms of infection. This makes estimations of seroprevalence in children difficult. Research is therefore required to determine the seroprevalence of SARS-CoV-2 antibodies in children. The primary objective of this study is to report the seroprevalence of SARS-CoV-2 $\lg M$ and/or IgG antibodies in healthy children at baseline, 2 months and 6 months. This is the only longitudinal UK study of seroprevalence in an exclusively paediatric population. Determining the changing seroprevalence is of vital public health importance and can help inform decisions around the lifting of paediatric specific social distancing measures such as school closures and the cancellation of routine paediatric hospital services.

Methods and analysis 1000 healthy children of healthcare workers aged between 2 and 15 years will be recruited from five UK sites (Belfast, Cardiff, Glasgow, London and Manchester). The children will undergo phlebotomy at baseline, 2 months and 6 months to measure lgM and/or lgG positivity to SARS-CoV-2. A sample size of 675 patients is required to detect a $5 \%$ change in seroprevalence at each time point assuming an alpha of 0.05 and a beta of 0.2. Adjusted probabilities for the presence of $\lg G$ and/or IgM antibodies and of SARS-CoV-2 infection will be reported using logistic regression models where appropriate.

Ethics and dissemination Ethical approval was obtained from the London - Chelsea Research Ethics Committee (REC Reference-20/HRA/1731) and the Belfast Health \& Social Care Trust Research Governance (Reference 19147TW-SW). Results of this study will be made available as preprints and submitted for publication in peer-reviewed journals. Trial registration number NCT0434740; Results

\section{INTRODUCTION}

\section{Background}

Coronaviruses are non-segmented positivestranded RNA viruses that primarily cause enzootic infections in mammals; ${ }^{12}$ however,

\section{Strengths and limitations of this study}

- This study is a large multicentre cohort study concerning the seroprevalence of $\lg \mathrm{G}$ and/or IgM antibodies to SARS-CoV-2 in children over 2 years of age.

- This is the only longitudinal UK study of seroprevalence in exclusively paediatric populations, and will provide important information that could help guide public health policy related to the COVID-19 pandemic.

- The geographic spread of sites across all four nations of the UK will provide detail of regional variation of seroprevalence.

- While chosen for practical reasons, the inclusion of only children of healthcare workers may limit the generalisability of this study to the whole population.

- A limitation of this study is that it is not powered to detect very small (less than $5 \%$ ) changes in seroprevalence.

in recent years, their transmission to humans has caused significant public health crises such as SARS in 2003 and the Middle East respiratory syndrome (MERS) in 2012. ${ }^{34}$ The novel coronavirus identified in Hubei province, China, in late 2019 was recognised to be in the same genus as those causing SARS and MERS and was named by the International Committee on Taxonomy of Viruses as SARS-CoV-2 in February 2020. The majority of patients infected with SARS-CoV-2 experience mild-to-moderate symptoms, but a proportion develop rapidly progressive acute respiratory distress syndrome and multiorgan failure. ${ }^{56} \mathrm{In}$ February 2020, the WHO named the disease caused by the SARS-CoV-2 virus as COVID-19. ${ }^{7}$

Children with SARS-CoV-2 infection typically have a milder clinical course than adults 
and are less likely to require hospitalisation. ${ }^{89}$ While this is reassuring, there have been rare reports of severe disease, specifically pneumonia, affecting children including a small number of deaths (two recorded deaths due to COVID-19 in the UK). ${ }^{1011}$ More recently, a disorder called 'paediatric inflammatory multisystem syndrome temporally associated with SARS-CoV-2' (PIMS-TS) has been described. ${ }^{12}$ This condition appears to be similar to Kawasaki disease. It is unclear if this is a novel condition or Kawasaki disease initiated by infection with SARS-CoV-2. ${ }^{13}$ While rare, PIMS-TS is of concern as some children have required admission to intensive care units. ${ }^{14}$

It is unclear, currently, what proportion of children have been exposed to SARS-CoV-2 in the UK. As already described, children have been relatively spared during the SARS-CoV-2 pandemic and overall they only account for $1.7 \%$ of reported cases in the USA, ${ }^{15} 1 \%$ of reported cases in the Netherlands ${ }^{16}$ and $2 \%$ of reported cases in the UK. ${ }^{17}$ These reported confirmed cases are unlikely to reflect the total number of exposed children due to the mild nature of COVID-19 in children. Infection survey pilots in the UK have shown no disparity in community cases of SARS-CoV-2 infection between adults and children $(0.24 \%$ whole population and $0.30 \%$ under the age of 19). ${ }^{18}$ A prospective seroprevalence study is therefore required to determine what proportion of children in the UK have been exposed to SARS-CoV-2, how long antibodies persist for and the symptoms associated with COVID-19 in healthy children.

A better understanding of the current seroprevalence is vital for implementing and withdrawing social distancing measures. Social distancing measures such as closure of schools and playgrounds, cancelling routine paediatric clinics and limited access to social care will have an effect on the physical and mental well-being of children. ${ }^{19} 20$ Deciding when normal services can be resumed is of paramount importance.

\section{Study design}

This multicentre observational prospective cohort study will determine the seroprevalence of SARS-CoV-2 antibodies in healthy children. This study protocol has been written in conjunction with the Strengthening the Reporting of Observational Studies in Epidemiology guidelines. $^{21}$ Data from each centre will be collected over a period of 6 months from enrolment. A non-probability sampling method will be used.

\section{Objectives}

1. Report the seroprevalence of SARS-CoV-2 IgM and/or IgG antibodies in healthy children aged 2-15 years at baseline, 2 months after enrolment and 6 months after enrolment.

2. Determine if antibodies persist at 2 months and 6 months.

3. Report the symptoms associated with COVID-19 in children.

\section{METHODS AND ANALYSIS}

\section{Setting}

Approximately 1000 participants will be recruited from five centres (Belfast, Cardiff, Glasgow, London and Manchester) between May and July 2020.

\section{Study sites}

- Belfast Health and Social Care Trust.

- Cardiff and Vale University Health Board.

- National Health Service, Greater Glasgow and Clyde.

- Public Health England (London).

- Manchester University National Health Service, Foundation Trust.

\section{Participants}

Children of healthcare workers who are aged between 2 and 15 years. For the purpose of this study, a healthcare worker is defined as an employee of the National Health Service (NHS). Healthcare workers will be categorised based on their role and if that role involves patient facing activities or not. A group of approximately 200 nonclinical and non-patient facing staff such as managerial staff and secretaries will be included to provide a comparison to clinical staff and improve the generalisability of the results. Participants will be recruited from each participating NHS organisation using internal intranet advertisements and email circulars.

Children currently receiving antibiotics, admitted to hospital within the last 7 days, receiving oral immunosuppressive treatment or ever diagnosed with a malignancy will be excluded.

\section{Informed consent}

Informed consent will be obtained prior to inclusion including assent from the child. The parent/child is free to decline/withdraw consent at any time without providing a reason and without being subject to any resulting detriment. For children who turn 16 during the follow-up period will be invited to consent for the study again. If the young person declines consent, he/she will be withdrawn from the study without being subject to any resulting detriment. Additional consent will be sought to store specimens for future research.

\section{Assessments and procedures}

The required assessments and procedures are outlined in table 1 . The proposed pathway is outlined in figure 1. All children will undergo phlebotomy at baseline and at 2 months and 6 months after enrolment. Children with suspected COVID-19 (based on governmental testing guidance) will undergo molecular testing for SARS-CoV-2.

\section{Phlebotomy}

All blood sampling/phlebotomy will be carried out by experienced paediatric medical and nursing professionals. Topical anaesthetic cream and distraction will be made available. A total of $5 \mathrm{~mL}$ of blood will be taken from each individual. 
Table 1 Assessment and procedures

\begin{tabular}{|c|c|}
\hline Assessment/procedure & Healthy children \\
\hline Consent discussion & In advance via telephone. \\
\hline Assessment of eligibility criteria & $\begin{array}{l}\text { In advance to attending initial clinic appointment via electronic consent form and } \\
\text { discussion with researcher. }\end{array}$ \\
\hline Phlebotomy & Baseline, 2 months and 6 months. \\
\hline Reverse transcription-PCR molecular testing & $\begin{array}{l}\text { When symptomatic arranged through current Public Health testing. Participants to } \\
\text { feedback results to researchers. }\end{array}$ \\
\hline
\end{tabular}

\section{Antibody testing}

Serum and/or plasma will be tested for IgG and IgM for SARS-CoV-2. Testing will be carried out at Public Health accredited laboratories using a range of assays including (but not limited to):

- Nucleocapsid assays-Abbott and Roche SARS-CoV-2 IgG assays.

- Spike protein assays-DiaSorin LIAISON SARSCoV-2 $\mathrm{S} 1 / \mathrm{S} 2 \mathrm{IgG}$.

Assay results will be reported as total titers and as a binary positive/negative based on manufacturers' suggested cut-off values.

\section{Molecular testing}

Molecular testing for SARS-CoV-2 using real-time reverse transcription quantitative PCR (RT-QPCR) is available for all children at all sites via existing testing strategies as part of the UK response to the COVID-19 pandemic. ${ }^{14}$ If a study participant develops symptoms of COVID-19, they will be asked to arrange a molecular test and feedback the result to the research team. This approach ensures that any participant testing positive for SARS-CoV-2 is included in the Public Health response.

\section{Data collection}

Study data will be collected and managed using Research Electronic Data Capture (REDCap) electronic data capture tools. ${ }^{22}$ Participants and their parents will provide information

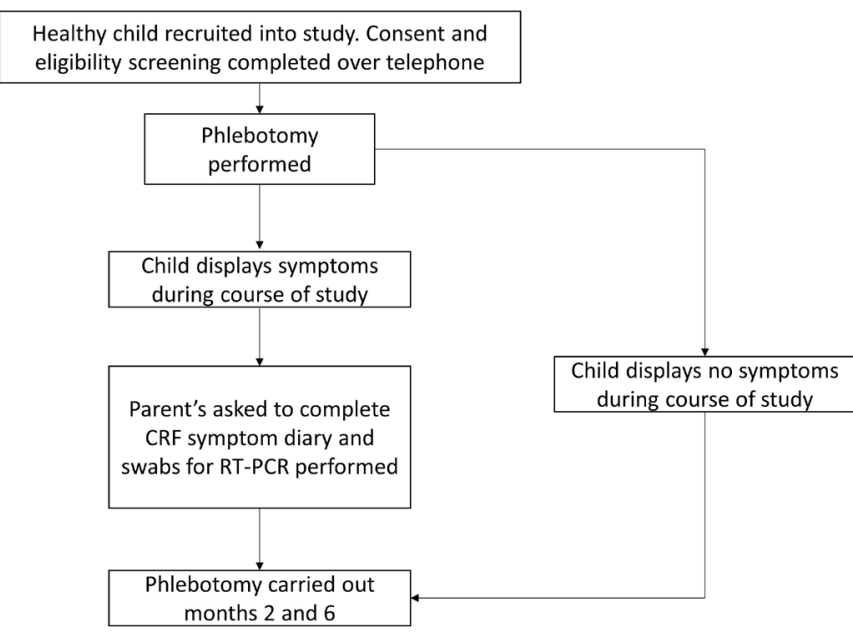

Figure 1 Clinical pathway for children enrolled in the study. relating to illness episodes, suspected household exposure to SARS-CoV-2 and the outcome of any molecular testing at each clinic appointment. Participants will be provided with electronic symptom diaries to record any illness episodes relating to possible COVID-19. Participants will be asked to record from their perceived first day of illness until their perceived last day of illness. In all instances, symptoms of illness episodes will be recorded prior to antibody test results being disclosed to minimise recall bias. (Copy of symptom diaries and RedCap case report forms are available in online supplemental files 1 and 2.)

\section{OUTCOME MEASURES}

\section{Primary outcome measure}

- Presence of IgG and/or IgM antibodies to SARS-CoV-2 in serum plasma.

\section{Secondary outcome measures}

- SARS-CoV-2 infection confirmed by RT-QPCR testing of oral/nasal swabs and/or crevicular fluid.

\section{Sample size justification}

For each site to be able to detect a change in prevalence at each timepoint of $10 \%$ (assuming an alpha of 0.05 and a beta of 0.2), 171 children are required at each site. Allowing for at least a $10 \%$ dropout rate, we estimate that each site will need to recruit approximately 200 patients. A total of 675 children are required from all sites to detect an overall change of $5 \%$ in seroprevalence across the entire population (assuming an alpha of 0.05 and a beta of 0.2). With five sites, we anticipate recruiting approximately 1000 children. Participants will be recruited via advertisements circulated on hospital intranet and social media. Participants will receive a certificate acknowledging their contribution to the study.

\section{Study registration}

This study was registered at https:/ /www.clinicaltrials.gov on 15 April 2020 (last updated on 27 May 2020). At the time of registration, no patients had been recruited to the study that opened on 6 May 2020. The end of the study will be the last study visit.

\section{Patient and public involvement (PPI)}

A PPI group comprising of parents and children that coined the term 'Covid-Warriors' has been convened. They have 
contributed to the design of the study through online surveys and video discussions. The PPI group will be involved with producing the lay summary and the dissemination of results.

\section{Data collection plan}

Data will be collected regarding the participant's age, sex, vaccination history and previous health. Data regarding potential predictors of seroconversion will be recorded including: known contact with individuals with COVID-19, contact with individuals who have been symptomatic and/ or self-isolating and results of any diagnostic testing such as molecular testing/antibody testing.

\section{Data storage and management}

Only anonymised non-personal data will be shared among the research team with personal data and linkage documentation remaining at the participating site under the care of the principle investigator. Data will be managed in accordance with General Data Protection Regulation (EU) 2016/679.

\section{Data sharing}

All the individual participant data collected during this study will be available (including data dictionaries) on the Queen's University Belfast data repository.

\section{Statistical analysis plan}

The study population will be described in terms of demographic characteristics with sex, median age and healthcare role of parents. Simple descriptive statistics (total number and proportion) will be used to describe symptomology, vaccination status and household contacts and seroprevalence of SARS-CoV-2 antibodies. Logistic regression modelling will be used to estimate the probability of the presence of SARS-CoV-2 antibodies, adjusting for factors including demographic features (age, gender) and symptomology (such as fever, cough, fatigue), which are deemed statistically significant.

\section{STUDY COMMITTEES}

\section{Steering committee}

A core study team comprising of the chief investigator and principle investigators at each site and statisticians have met and will meet regularly to monitor and report on the conduct of the study. Responsibilities include: agreeing the final study protocol, reviewing progress of the study and agreeing any changes to the protocol, data verification and publication of study reports.

\section{Data monitoring committee}

The principle investigators and statisticians will meet after each clinic appointment (baseline, 2 months and 6 months) to discuss the data, identify any missing data and perform an interim analysis.

\section{Adverse events}

The study involves phlebotomy and swab testing only and no medicinal products are being administered. The likelihood of adverse events is low. All adverse events will be logged and reported by the principle investigator at each site. Any serious adverse events will be reported to the chief investigator who will notify the study sponsor (Queen's University Belfast).

\section{Protocol deviations and serious breaches}

A deviation from the approved protocol will be recorded by the principle investigator at each site. Any serious breaches that could affect the safety or study participants must be reported to the chief investigator and sponsor. The sponsor will then determine if escalation to the research ethics committee is required.

\section{Expenses and benefits}

There is no reimbursement or benefit for participants taking part in this study. Children who participate in the study will receive a 'COVID WARRIOR' certificate acknowledging their contribution.

\section{Strengths and limitations}

The strength of this study is that it is a large multicentred prospective cohort seroprevalence study that will report the changing seroprevalence of SARS-CoV-2 antibodies over the coming months. The geographic spread of sites across the entire UK will provide detail on regional variations in seroprevalence and will provide data useful to devolved nations.

The study is potentially limited ias it is not powered to detect very small changes in seroprevalence (less than 5\%). The results may not be generalisable to the entire population as the included participants are all children of healthcare workers. Children of healthcare workers were however chosen because the consent processes and preparation for phlebotomy will be easier among healthcare workers than the general population. The current social distancing restrictions make face-to-face consent discussions and the use of play therapists difficult. By recruiting children of healthcare workers those consent discussions are likely to be easier, due to a greater prior knowledge. Healthcare workers are also more likely to have a better insight into the study procedures and how to prepare children for phlebotomy.

\section{ETHICS AND DISSEMINATION \\ Publication plan}

The final manuscripts will be published as preprints and for publication in high-impact medical journals and presented at medical conferences. The PPI group will be involved with the dissemination of the result findings and contribute to the lay summary. Authorship will be granted to those individuals who contribute in a meaningful way as judged by the study steering committee.

\section{Potential risks/benefits}

Additional distress from phlebotomy will be minimised by the use of experienced paediatric healthcare professionals and topical anaesthetic creams. Parents can choose decline any procedure at any time. There are no benefits for the participants in this study.

\section{Research ethics and governance}

The London-Chelsea Research Ethics Committee (REC Reference-20/HRA/1731) and the Belfast Health \& Social 
Care Trust Research Governance (Reference 19147TW-SW) both provided favourable reviews. The study is sponsored by Queen's University Belfast. Amendments to the protocol will be submitted to the sponsor for categorisation. Substantial amendments will be submitted for review by the Research Ethics Committee.

\section{Author affiliations}

${ }^{1}$ Department of Nephrology, Belfast Health and Social Care Trust, Belfast, United Kingdom

${ }^{2}$ Paediatric Infectious Diseases, Royal Belfast Hospital for Sick Children, Belfast, United Kingdom

${ }^{3}$ Wellcome-Wolfson Institute for Experimental Medicine, Queen's University BelfastSchool of Medicine, Dentistry and Biomedical Sciences, Belfast, UK ${ }^{4}$ Emergency Department, Royal Belfast Hospital for Sick Children, Belfast, United Kingdom

${ }^{5}$ Regional Virus Laboratory, Belfast Health and Social Care Trust, Belfast, United Kingdom

${ }^{6}$ Immunisation and Countermeasures Division, Public Health England, London, UK

${ }^{7}$ Emergency Department, Bristol Royal Hospital for Children, Bristol, UK

${ }^{8}$ Faculty of Health and Applied Science, University of the West of England, Bristol, UK

${ }^{9}$ Mathematical Sciences Research Centre, Queen's University Belfast School of

Mathematics and Physics, Belfast, UK

${ }^{10}$ General Paediatrics, Belfast Health and Social Care Trust, Belfast, UK

${ }^{11}$ Emergency Department, Royal Hospital for Children, Glasgow, UK

${ }^{12}$ Paediatric Infectious Disease and Immunology, Cardiff and Vale University Health

Board, Cardiff, UK

${ }^{13}$ Emergency Department, Children's Health Ireland, Dublin, Ireland

\section{Twitter Mark David Lyttle @mdlyttle}

Acknowledgements St Jude Children's Cancer Aid and Research Institute. Elizabeth Waxman, RSCN, BSc (PICU), EN Paediatric Research Nurse, Manager Glasgow Clinical Research Facility and the staff of the Glasgow Clinical Research Facility. Zoe Morrison, Hannah Davies, Sonia Goyal, Aiden Moore, Laura Price, Phillippa Robb, Ben Saunders, Deborah Sankey, Coral Rees, Sally Richards and Catrin Kruppa. Cardiff and Vale University Health Board, Cardiff.

Funding This work was supported by Health and Social Care, Research and Development Division, Public Health Agency Ref: COM/5596/20. This funding source had no role in the design of this study and will not have any role during its execution, analyses, interpretation of the data or decision to submit result.

Competing interests JMK holds share options in Hibergene Diagnostics Ltd, Sandyford, Dublin, Republic of Ireland. DF is a non-executive director, advisory board member and shareholder in Hibergene Diagnostics Ltd, Sandyford, Dublin, Republic of Ireland.

\section{Patient consent for publication Not required.}

Provenance and peer review Not commissioned; externally peer reviewed.

Supplemental material This content has been supplied by the author(s). It has not been vetted by BMJ Publishing Group Limited (BMJ) and may not have been peer-reviewed. Any opinions or recommendations discussed are solely those of the author(s) and are not endorsed by BMJ. BMJ disclaims all liability and responsibility arising from any reliance placed on the content. Where the content includes any translated material, BMJ does not warrant the accuracy and reliability of the translations (including but not limited to local regulations, clinical guidelines, terminology, drug names and drug dosages), and is not responsible for any error and/or omissions arising from translation and adaptation or otherwise.

Open access This is an open access article distributed in accordance with the Creative Commons Attribution Non Commercial (CC BY-NC 4.0) license, which permits others to distribute, remix, adapt, build upon this work non-commercially, and license their derivative works on different terms, provided the original work is properly cited, appropriate credit is given, any changes made indicated, and the use is non-commercial. See: http://creativecommons.org/licenses/by-nc/4.0/.

\section{ORCID IDs}

Michael Corr http://orcid.org/0000-0001-9272-2323

Mark David Lyttle http://orcid.org/0000-0002-8634-7210

\section{REFERENCES}

1 Huang C, Wang Y, Li X, et al. Clinical features of patients infected with 2019 novel coronavirus in Wuhan, China. Lancet 2020;395:497-506.

2 Schoeman D, Fielding BC. Coronavirus envelope protein: current knowledge. Virol J 2019;16:69.

3 Donnelly CA, Ghani AC, Leung GM, et al. Epidemiological determinants of spread of causal agent of severe acute respiratory syndrome in Hong Kong. Lancet 2003;361:1761-6. 3.

4 Cauchemez S, Fraser C, Van Kerkhove MD, et al. Middle East respiratory syndrome coronavirus: quantification of the extent of the epidemic, surveillance biases, and transmissibility. Lancet Infect Dis 2014;14:50-6.

5 Wang D, Hu B, Hu C, et al. Clinical characteristics of 138 hospitalized patients with 2019 novel CoronavirusInfected pneumonia in Wuhan, China. JAMA 2020.

6 Hui DSC, Zumla A. Severe acute respiratory syndrome: historical, epidemiologic, and clinical features. Infect Dis Clin North Am 2019;33:869-89.

7 WHO. Coronavirus disease 2019 (COVID-19): situation report-41, 2020. Available: https://www.who.int/docs/default-source/ coronaviruse/situation-reports/20200301-sitrep-41-covid-19.pdf [Accessed 4 Apr 2020].

8 Livingston E, Bucher K. Coronavirus disease 2019 (COVID-19) in Italy. JAMA 2020;323:1335 http://jamanetwork.com/journals/jama/ fullarticle/2763401

9 Dong Y, Mo X, Hu Y, et al. Epidemiological characteristics of 2143 pediatric patients with 2019 coronavirus disease in China. Pediatrics 2020:e20200702

10 Lu X, Zhang L, Du H, et al. SARS-CoV-2 infection in children. $N$ Engl J Med 2020;382:1663-5 https://www.nejm.org/doi/full/

11 Office of National Statistics. Provisional counts of the number of deaths registered in England and Wales, including deaths involving the coronavirus (COVID-19), by age, sex and region, in the latest weeks for which data are available week ending 15 may 2020. statistical Bulletin. Available: https://www.ons.gov.uk/peoplepopula tionandcommunity/birthsdeathsandmarriages/deaths/bulletins/deat hsregisteredweeklyinenglandandwalesprovisional/latest

12 Royal College of Paediatrics and Child Health. Guidance-Paediatric multisystem inflammatory syndrome temporally associated with COVID-19, 2020. Available: https://www.rcpch.ac.uk/resources/ guidance-paediatricmultisystem-inflammatory-syndrome-temporallyassociated-covid-19

13 Verdoni L, Mazza A, Gervasoni A, et al. An outbreak of severe Kawasaki-like disease at the Italian epicentre of the SARS-CoV-2 epidemic: an observational cohort study. Lancet 2020;395:1771-8 https://doi.org/

14 Riphagen S, Gomez X, Gonzalez-Martinez C, et al. Hyperinflammatory shock in children during COVID-19 pandemic. Lancet 2020;395:1607-8 https://doi.org/

15 CDC COVID-19 Response Team. Coronavirus Disease 2019 in Children United States, February 12-April 2, 2020. MMWR Morb Mortal Wkly Rep 2020;69:422-6. . 2.

16 Children and COVID-19. Amsterdam: National Institute for public health and the environment (RIVM), 2020. Available: https://www.rivm.nl/en/ novelcoronavirus-covid-19/children-and-covid-19

17 Docherty AB, Harrison EM, Green CA, et al. Features of 16,749 hospitalised UK patients with COVID-19 using the ISARIC who clinical characterisation protocol. medRxiv 2020.

18 Office of National Statistics. Coronavirus (COVID-19) infection survey pilot: England, 10 may 2020 estimates of people testing positive for the coronavirus (COVID-19) in England. results from COVID-19 infection survey pilot. statistical Bulletin, 2020. Available: https://www.ons.gov.uk/ peoplepopulationandcommunity/healthandsocialcare/conditionsanddis eases/bulletins/coronaviruscovid19infectionsurvey/england

19 Cohen J, Kupferschmidt K. Countries test tactics in 'war' against COVID-19. Science 2020;367:1287-8.

20 Wang G, Zhang Y, Zhao J, et al. Mitigate the effects of home confinement on children during the COVID-19 outbreak. Lancet 2020;395:945-7.

21 von Elm E, Altman DG, Egger M, et al. The strengthening the reporting of observational studies in epidemiology (STROBE) statement: guidelines for reporting observational studies. Lancet 2007;370:1453-7.

22 Harris PA, Taylor R, Thielke R, et al. Research electronic data capture (REDCap)--a metadata-driven methodology and workflow process for providing translational research informatics support. J Biomed Inform 2009;42:377-81 http://www.ncbi.nlm.nih.gov/pubmed/18929686 